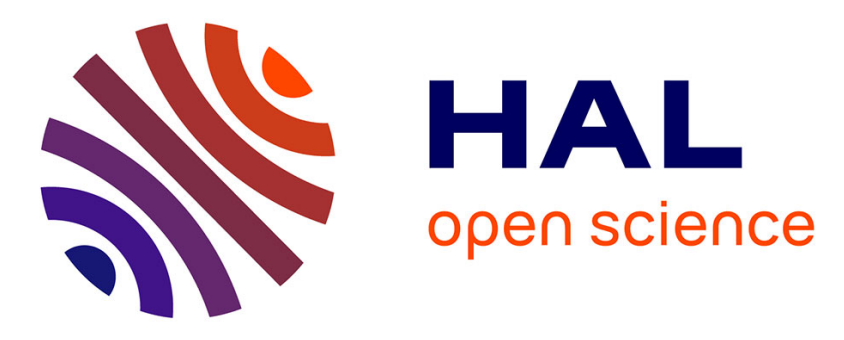

\title{
Determining the effective density of airborne nanoparticles using multiple charging correction in a tandem DMA/ELPI setup
}

Sébastien Bau, Denis Bémer, Florence Grippari, Jean-Christophe

Appert-Collin, Dominique Thomas

\section{To cite this version:}

Sébastien Bau, Denis Bémer, Florence Grippari, Jean-Christophe Appert-Collin, Dominique Thomas. Determining the effective density of airborne nanoparticles using multiple charging correction in a tandem DMA/ELPI setup. Journal of Nanoparticle Research, 2014, 16, pp.2629. 10.1007/s11051014-2629-2 . hal-01140067

\section{HAL Id: hal-01140067 \\ https://hal.science/hal-01140067}

Submitted on 7 Apr 2015

HAL is a multi-disciplinary open access archive for the deposit and dissemination of scientific research documents, whether they are published or not. The documents may come from teaching and research institutions in France or abroad, or from public or private research centers.
L'archive ouverte pluridisciplinaire HAL, est destinée au dépôt et à la diffusion de documents scientifiques de niveau recherche, publiés ou non, émanant des établissements d'enseignement et de recherche français ou étrangers, des laboratoires publics ou privés. 


\section{Determining the effective density of airborne nanoparticles using multiple charging correction in a tandem DMA/ELPI setup}

\section{Brief communication}

Sébastien Bau ${ }^{1}$, Denis Bémer ${ }^{1}$, Florence Grippari ${ }^{2}$, Jean-Christophe AppertCollin $^{2}$ and Dominique Thomas ${ }^{2}$

${ }^{1}$ Institut National de Recherche et de Sécurité, Rue du Morvan CS 60027, 54519 Vandoeuvre, France

sebastien.bau@inrs.fr

${ }^{2}$ Laboratoire de Réactions et Génie des Procédés - Université de Lorraine, 1, rue Grandville - BP 20451, 54001 Nancy Cedex, France

Keywords: nanoaerosol; effective density; electrical mobility diameter; aerodynamic diameter; tandem DMA/ELPI 


\section{Abstract}

Increasing numbers of workers are exposed to airborne nanoparticles, the health effects of which remain difficult to evaluate. Effective density is considered to be a key characteristic of airborne nanoparticles due to its role in particle deposition in the human respiratory tract and in the conversion of number distributions to mass distributions. Because effective density cannot be measured directly, in this study the electrical mobility and aerodynamic equivalent diameters of airborne nanoparticles were measured simultaneously (tandem DMA/ELPI). Test aerosols consisted of spherical Di-Ethyl-Hexyl-Sebacate nanoparticles produced by nebulization (PALAS AGK 2000). To take into account the presence of multiply-charged particles at the DMA outlet, a theoretical model was developed in which the successive mechanisms undergone by particles are accounted for. Using this model, it is possible to determine the proportion of each population exiting the DMA ( $p=1,2, \ldots 5$ elementary charges) in each channel of the overall ELPI signal. Thus, particle effective density can be estimated for each population. The results indicate that using the ELPI signal alone could lead to significant misevaluation of particle effective density, with biases up to $150 \%$. However, when the proportion of each population is taken into account, particle effective density is determined within $\pm 15 \%$ of the theoretical value. 


\section{Introduction}

Over the last 20 years, nanomaterials have been increasingly developed and used in many technology and industry sectors, including medicine, consumer products, energy, materials and manufacturing, food packaging, automotive, etc. This has raised new challenges related to the health and safety risks associated with these substances. As yet, the health effects of nanoparticles are incompletely characterized. In addition, assessing occupational exposure to airborne nanoparticles is difficult as their behavior has not yet been fully described or understood.

Among the key characteristics of airborne nanoparticles, effective density plays a role in particle motion in air and in the relationship between number distributions and mass distributions (Mc Murry et al., 2002). Moreover, particle deposition in the human respiratory tract (ICRP, 1994; NCRP, 1997) is mainly governed by effective density and particle shape. Thus, spherical 50-nm particles with different densities deposit differently in the alveolar region of the lung: with a density of 5, the deposited fraction will be $12 \%$; at unit density, $35 \%$ of particles will deposit; and at a density of $0.2,51 \%$ of the particles will be deposited. The density also affects the optical properties of particles through their refractive index. This property is used to convert optical particle counter data (Hand and Kreidenweis, 2002; Schmid et al., 2007).

Since effective density cannot be measured directly, various methods have been developed to accede to this parameter. Among them, measurement of the mass of sizeselected particles, typically achieved by combining DMA (Differential Mobility Analyzer) with an Aerosol Particle Mass analyzer (APM, see e.g. Ehara et al., 1996) tandem DMA/APM (e.g. Mc Murry et al., 2002; Ku et al., 2006; Pagels et al., 2009; Kim et al., 2009; Ku and Kulkarni, 2012; Shapiro et al., 2012; Rissler et al., 2013; Charvet et al., 2014). Measured particle diameter and mass are basic parameters which should simplify data collection and interpretation. However, this approach is time-consuming, requiring one hour to provide the particle effective density for a given particle size. Furthermore, the APM cannot readily be used alone as it is based on a principle requiring the use of both a DMA and a particle detector, at least.

Another approach to measure effective density combines the mobility equivalent diameter measured by a Scanning Mobility Particle Sizer (SMPS) with either the corresponding aerodynamic diameter (using a Time-Of-Flight technique) or the particle mass (Mass Spectrometer). This is known as SMPS/AMS (e.g. Katrib et al., 2005). Better results 
were obtained by replacing the SMPS by a DMA, measuring the density of spherical particles with high precision (e.g. Zelenyuk et al., 2005, 2006).

In this work, the aerodynamic and the electrical mobility diameters of an aerosol were measured simultaneously. A similar approach combining a DMA and an impactor was proposed in the 1990s (Kelly and Mc Murry, 1992; Stein et al., 1994). This method was further studied by Hand and Kreidenweis (2002) who used an aerodynamic particle sizer (APS) to determine the aerodynamic equivalent diameter of size-selected particles, although the APS has a limited size range in the submicron scale. The Electrical Low Pressure Impactor (ELPI) was developed in 1992 by Keskinen et al. (1992). It is an instrument capable of measuring the size distribution of aerosols in a range from $30 \mathrm{~nm}$ to $10 \mu \mathrm{m}$ across 12 channels in real-time. Thus, the DMA/ELPI combination seemed better adapted to airborne submicron particles. Another advantage is that the DMA/ELPI combination can rapidly determine the effective density of airborne particles thanks to the $1 \mathrm{~Hz}$ time resolution of the ELPI. DMA and ELPI instruments can also be used independently for metrological purposes or to characterize workplace aerosols. This combination of instruments has been used by several authors to measure the effective density of various aerosols, such as diesel exhaust (e.g. Ahlvik et al., 1998; Maricq et al., 2000; Van Gulijk et al., 2004), atmospheric aerosols (e.g. Mc Murry et al., 2002), soot agglomerates (e.g. Skillas et al., 1999), or metal particles with varying morphologies (e.g. Ristimäki et al., 2002; Virtanen et al., 2004; Ristimäki and Keskinen, 2006).

The main limitations of this setup are due to the low flow rate $\left(0.3 \mathrm{~L} \cdot \mathrm{min}^{-1}\right)$ imposed by the DMA. This requires a large dilution factor which may cause concentrations to fall below the limit of quantification of the ELPI. In addition, the cascade impactor has a limited size resolution, particles may deposit on multiple stages (stage overlapping, e.g. Dong et al., 2004), particles may be lost (Virtanen et al., 2001) or bounce (e.g. Virtanen et al., 2011; Huuluvainen et al., 2013). To take into account most of these bias sources, complex inversion algorithms may be necessary (e.g. Bau and Witschger, 2013).

To date, no harmonised protocol or methodology has been presented for tandem DMA/ELPI when measuring particle effective density. In particular, it remains unclear whether the particle aerodynamic diameter as derived from the ELPI should be based on the current (raw data) or the number size distribution. The number concentration in each channel is calculated through the density-dependent charging law. Consequently, if the raw current distribution measured by the ELPI is not used, an assumption must be made on particle density (Maricq et al., 2006). Furthermore, the presence of multiple charged 
particles at the outlet of the DMA, and consequently integrated into the ELPI signal, should be taken into account to avoid possible bias in estimation of particle effective density.

This work provides a new method based on multiple charge correction to determine the nanoparticle effective density using a tandem DMA/ELPI setup. A model is proposed where the proportion of each population exiting the DMA $(p=1,2, \ldots 5$ elementary charges) in each channel of the overall ELPI signal can be extracted. The method is first validated using a theoretical case, and then applied to measure the effective density of spherical particles. 


\section{Theoretical background: determining particle effective density based on simultaneous measurement of the electrical mobility and aerodynamic equivalent diameters}

The effective density $\left(\rho_{e}\right)$ of particles can be determined by simultaneously measuring the electrical mobility $\left(d_{m}\right)$ and aerodynamic $\left(d_{a}\right)$ equivalent diameters according to (DeCarlo et al., 2004):

$\rho_{e}=\frac{C u\left(d_{a}\right) d_{a}^{2}}{C u\left(d_{m}\right) d_{m}^{2}} \rho_{0}$

where $C u$ is the slip correction coefficient and $\rho_{0}$ the reference density $\left(\rho_{0}=1 \mathrm{~g} \cdot \mathrm{cm}^{-3}\right)$. To accede to both of these equivalent diameters, the combination of a DMA and an ELPI placed in series was chosen.

More precisely, the methodology proposed in this paper relies on the measurement of the overall particle number size distribution (by means of a SMPS). The selection of particles according to their electrical mobility (by using a DMA) as well as their corresponding aerodynamic current distribution (thanks to an ELPI) is modeled. Thus, in our approach, the measured ELPI signal is only used for validating the results stemming from theoretical calculations.

Based on an aerosol number size distribution, noted $C_{N_{0}}\left(d_{m}\right)$, as measured by a SMPS, the following paragraphs and the flowchart in Figure 1 describe the procedure by which the corresponding ELPI signal downstream of a DMA can be calculated. This theoretical signal is then further used to determine particle effective density.

\section{Figure 1}

It should be noticed that only grey boxes in Figure 1 correspond to experimental data. As mentioned above, it can be observed that ELPI data are not explicitly required to determine particle effective density; these data are involved in the validation step, as described later in this paper.

\section{Step 1: Determining the aerosol at the outlet of the DMA}

The aerosol can be characterized at the outlet of the DMA based on (a) the electrical state-of-charge of the particles after passing through the neutralizer, and (b) the transfer function of the DMA itself. 


\section{Step 1a: Neutralization of the aerosol at the inlet}

The DMA selects particles based on electrical deviation of electrically-charged particles by an electric field between concentric electrodes. As a consequence, the aerosol must be brought at given electrical state-of-charge at the inlet of the DMA. This is commonly achieved using a radioactive source that will generate bipolar ions. These ions will fix onto the particles' surface, giving them an overall neutral state-of-charge. This is known as the Boltzmann equilibrium (e.g. Baron \& Willeke, 2001). This equilibrium can be used to describe the fraction, $f_{p}$, of particles of a given size, $d_{m}$, carrying $p$ elementary charges based on:

$f_{p}\left(d_{m}\right)=\frac{\exp \left(-\frac{K_{E} \cdot p^{2} \cdot e^{2}}{K_{B} \cdot T \cdot d_{m}}\right)}{\sum_{n=-\infty}^{n=+\infty} \exp \left(-\frac{K_{E} \cdot n^{2} \cdot e^{2}}{K_{B} \cdot T \cdot d_{m}}\right)}$

where $K_{B}$ is Boltzmann's constant, $T$ is the absolute temperature, $e$ is the elementary charge $\left(e=1.602 \times 10^{-19} \mathrm{C}\right)$ and $K_{E}$ is the electrical constant $\left(K_{E}=9 \times 10^{9} \mathrm{~N} \cdot \mathrm{m}^{2} \cdot \mathrm{C}^{-2}\right)$.

\section{Step 1b: Particle size selection}

Once neutralized, particles pass through the DMA where they are deviated according to their electrical mobility, $Z$, which is defined by:

$Z\left(p, d_{m}\right)=\frac{p \cdot e \cdot K_{B} \cdot T \cdot C u\left(d_{m}\right)}{3 \pi \cdot \eta_{g} \cdot d_{m}}$

with $\eta_{g}$ the viscosity of the surrounding gas. A specific particle mobility can be selected by setting the inner electrode of the DMA to a given voltage. Although it is commonly considered that fixed particle mobility is equivalent to the size of a single particle, various mechanisms result in a polydisperse aerosol being emitted at the outlet of the DMA.

The first of these is related to the separation efficiency of the DMA, known as the transfer function. Thus, when selecting particles with fixed electrical mobility $Z$, particles with a mobility of $Z+\Delta Z$ will also be emitted from the DMA, although to a lesser extent. The probability $\eta_{\mathrm{DMA}}(Z)$ that a particle of given electrical mobility, $Z$, will exit the DMA has been modeled by several authors (Stolzenburg, 1988; Stratmann, 1997; Heim et al., 2004). This probability is generally described by a triangular function, defined by following equation (Martinsson et al., 2001):

$\eta_{\mathrm{DMA}}(Z)=\left\{\begin{array}{cc}\lambda \cdot \mu \cdot\left[1+\mu \cdot \frac{Q_{s h}}{Q_{a}}\left(\frac{Z}{z_{0}}-1\right)\right] & \text { for } 1-\frac{Q_{a}}{\mu \cdot Q_{s h}} \leq \frac{Z}{z_{0}} \leq 1 \\ \lambda \cdot \mu \cdot\left[1-\mu \cdot \frac{Q_{s h}}{Q_{a}}\left(\frac{Z}{z_{0}}-1\right)\right] & \text { for } 1 \leq \frac{Z}{z_{0}} \leq 1+\frac{Q_{a}}{\mu \cdot Q_{s h}} \\ 0 & \text { otherwise }\end{array}\right.$ 
where $Z_{0}$ corresponds to the selected electrical mobility, $\mu$ to the broadening parameter and $\lambda$ to the loss parameter $(0 \leq \lambda, \mu \leq 1)$. In this equation, $Q_{a}$ represents the aerosol flow rate, and $Q_{s h}$ the sheath flow rate. The $Q_{s h} / Q_{a}$ ratio was set to 10 in this study.

The second mechanism causing polydisperse aerosol emission stems from the presence of multiply-charged particles with the same electrical mobility as singly charged particles. For example, according to equation (3), 156-nm particles with 2 elementary charges have the same electrical mobility as 100-nm particles carrying 1 elementary charge.

Thus, at the outlet of the DMA, the number size distribution of particles carrying $p$ elementary charges corresponds to:

$C_{N}\left(p, d_{m}\right)=C_{N_{0}}\left(d_{m}\right) \cdot f_{p}\left(d_{m}\right) \cdot \eta_{\mathrm{DMA}}\left(p, d_{m}\right)$

\section{Step 2: Calculation of the corresponding ELPI signal}

Within the ELPI, particles undergo (a) a positive corona charging step and (b) 13 successive impaction steps.

\section{Step 2a: Particle charging}

In the ELPI, airborne particles are first drawn into a unipolar corona charger $(+5 \mathrm{kV})$ by a vacuum pump at $10 \mathrm{~L} \cdot \mathrm{min}^{-1}$. Here, they are positively charged to a defined level according to their mobility equivalent diameter (Moisio, 1999; Marjamäki et al., 2000):

$E_{c h}\left(d_{m}\right)=\frac{Q}{10} \cdot \begin{cases}4.48 \cdot d_{m}{ }^{1.9087} & \text { for } d_{m}<0.095 \mu \mathrm{m} \\ 1.2930 \cdot d_{m}{ }^{1.3805} & \text { for } 0.095<d_{m}<1.196 \mu \mathrm{m} \\ 1.3529 \cdot d_{m}{ }^{1.1308} & \text { for } d_{m}>1.196 \mu \mathrm{m}\end{cases}$

where $Q$ is expressed in L.min ${ }^{-1}$.

It is important to note that the particles exiting the DMA and thus entering the ELPI's charger are negatively charged. Qi et al. (2009) indicate that after passage through the charger, particles which were previously negatively charged end up with the same number of charges as particles which were initially neutral. This is because positive ions are strongly attracted to negative particles, resulting in a very high combination coefficient. Although their study was carried out by using the NSAM (TSI model 3550) charger for particles down to $50 \mathrm{~nm}$, it will be assumed in the remainder of this paper that their observations are also valid for the ELPI. 


\section{Step 2b: Cascade impaction}

The charged particles are then size-classified from $30 \mathrm{~nm}$ to $10 \mu \mathrm{m}$ in a 13-stage channel, multi-jet, low pressure impactor based on their aerodynamic equivalent diameter. A 12channel electrometer is used to measure the charges carried by the particles impacted on each stage. All stages are electrically insulated from each other.

At this point in time, the behavior of airborne particles is mainly governed by their inertial properties; thus, their effective density is a key characteristic when calculating particle deposition within the cascade impactor.

According to Marjamäki et al. (2005), the global collection efficiency of stage $i$ in the impactor is given by:

$E_{i}=1-\left(1-E_{i}^{P}\right) \cdot\left(1-E_{i}^{D}\right) \cdot\left(1-E_{i}^{I M}\right) \cdot\left(1-E_{i}^{S C}\right)$

where $E_{i}^{P}$ corresponds to particle collection by impaction, $E_{i}^{D}$ by diffusion, $E_{i}^{I M}$ by image forces and $E_{i}^{S C}$ by space-charge effects. For mathematical details, see Marjamäki et al. (2005). The probability that a particle of diameter $d_{a}$ will be collected on stage $i$ is therefore calculated by the following equation:

$k_{i}\left(d_{a}\right)=E_{i}\left(d_{a}\right) \cdot \prod_{j=i+1}^{j=13}\left[1-E_{j}\left(d_{a}\right)\right] \quad i=1, \ldots, 12$

\section{Step 2c: Corresponding current distribution}

The resulting current corresponds to the product of the deposition probability, the inlet number concentration and the charging efficiency:

$I_{i}\left(p, d_{a}\right)=\sum_{d_{m}} k_{i}\left(d_{a}\right) \cdot C_{N}\left(p, d_{m}\right) \cdot E_{c h}\left(d_{m}\right)$

For each population $(p=1, \ldots, 5)$ at the outlet of the DMA, the equations presented above make it possible to determine the corresponding current distribution in the ELPI. Combining equations (5) and (9) leads to an expression providing the total current on stage $i$ for population $p$ :

$I_{i}\left(p, d_{a}\right)=\sum_{d_{m}} k_{i}\left(d_{a}\right) \cdot C_{N_{0}}\left(d_{m}\right) \cdot f_{p}\left(d_{m}\right) \cdot \eta_{\mathrm{DMA}}\left(p, d_{m}\right) \cdot E_{c h}\left(d_{m}\right)$

\section{Step 3: Deriving particle effective density}

Based on the current distributions calculated using equation (10), the median aerodynamic diameter can be determined for each population. No lognormal fit/optimization was applied in this step to avoid assumptions on the shape of the distribution. Instead, linear regressions between the data points surrounding the 50\%percentile of the cumulative current distributions, $I_{c u m}\left(p, d_{a}\right)$, were used, i.e.:

$$
I_{\text {cum }}=a \cdot \ln \left(d_{a}\right)+b
$$


with $a$ and $b$ being constants that differ for each population considered. Therefore, each median aerodynamic diameter is given by:

$$
d_{a}=\exp \left[\frac{0.5-b}{a}\right]
$$

Let us consider Figure $3 \mathrm{~b}$ as an example, where the cumulative currents (dashed line, right axis) surrounding the 50\%-percentile are 0.0941 and 0.726 for aerodynamic diameters of $94 \mathrm{~nm}$ and $158 \mathrm{~nm}$, respectively. The linear regression leads to $a=1.22$ and $b=-5.43$, which results in a median aerodynamic diameter of $131 \mathrm{~nm}$ (as stated in Table 1).

The equivalent electrical mobility diameter $\left(d_{m}\right)$, set in the DMA, and the corresponding aerodynamic diameter $\left(d_{a}\right)$, resulting from impaction in the ELPI, can then be introduced into equation (1) to determine the effective density of particles. The ELPI data taken in this step are not measured but calculated by means of the aforementioned equations (210), which makes it possible to determine the proportion of each population in each stage, as depicted in Figure 1.

For spherical particles, this approach is interesting because it allows their density to be determined multiple times; indeed, for each population, this parameter can be obtained simultaneously. In other words, selecting one electrical mobility in the DMA allows not only the effective density of singly charged particles to be determined, but also the one of multiply charged populations, whose electrical mobility diameters are larger, as defined by equation (3). For each couple of data $d_{m}\left(Z_{0}, p\right), d_{a}(p)$, the effective density can thus be determined.

For the case of agglomerates/aggregates, effective density is expected to decrease with increasing particle diameter. As a consequence, for a given electrical mobility fixed in the DMA, this method should be able to provide the decrease in effective density when considering multiply-charged particles, i.e., one power law for each condition.

\section{Example of application with a theoretical aerosol}

Let us consider a theoretical aerosol containing spherical particles with a density of $\rho_{e}=2 \mathrm{~g} . \mathrm{cm}^{-3}$, distributed according to a lognormal distribution with a mode of $100 \mathrm{~nm}$, a geometric standard deviation of 1.8 , and a total concentration of $10^{6} \# . \mathrm{cm}^{-3}$, referenced $C_{N_{0}}\left(d_{m}\right)$ in Figure 2. This size distribution is assumed to be the result of a SMPS measurement as stated in Figure 1.

Selecting a size of $75 \mathrm{~nm}$ in the DMA leads to a total outlet concentration of $9.210^{3}$ \#.cm

${ }^{3}$, containing $76 \%$ singly charged particles, $21 \%$ doubly charged particles, and $3 \%$ triply charged particles (Figure 2). 


\section{Figure 2}

Once charged by the ELPI charger, these proportions are significantly modified due to the charging law giving more weight to larger particles. The contribution of singly charged particles to the total current thus becomes $60 \%$, while it is $32 \%$ for doubly charged particles, and $7 \%$ for triply charged particles.

After impaction onto the different stages of the ELPI, the total current distribution can be computed (Figure 3a). The current distribution for singly charged and doubly charged particles is displayed in Figure $3 \mathrm{~b}$ and $3 \mathrm{c}$, respectively. They have been calculated by setting $p=1$ and $p=2$ in equations (2) to (10), respectively.

\section{Figure 3}

The cumulative distributions present median aerodynamic diameters of $155 \mathrm{~nm}, 131 \mathrm{~nm}$ and $193 \mathrm{~nm}$ for total, singly- and doubly-charged populations, respectively (Table 1). The corresponding electrical mobility diameters can for each population then be calculated using equation (3). The relative discrepancies between computed effective densities $\left(\rho_{e}^{\text {calc }}\right)$ and reference density $\left(\rho_{e}=2 \mathrm{~g} \cdot \mathrm{cm}^{-3}\right)$ were expressed as:

$\Delta=\frac{\rho_{e}^{\text {calc }}-\rho_{e}}{\rho_{e}} \cdot 100$

\section{Table 1}

The data shown in Table 1 indicate that determining particle effective density based on the fraction of $p$-charged particles is more accurate than considering the overall aerosol. Indeed, whatever the population considered, the relative discrepancies were found to be below $7 \%$, while the relative bias reached almost $30 \%$ when the same calculation was performed on the total current. 


\section{Materials and methods}

\section{Experimental setup}

The method was validated using test aerosols of spherical Di-Ethyl-Hexyl-Sebacate (DEHS) nanoparticles produced by nebulization (PALAS AGK 2000).

Preliminary measurements were performed with a SMPS (Grimm Vienna Type M-DMA, Grimm Condensation Particle Counter model 5.403) to determine the number size distribution of the aerosol (noted $C_{N_{0}}\left(d_{m}\right)$ in the previous section). Although not perfectly lognormal, the number size distribution presented a mode of $191 \mathrm{~nm}$ and a geometric standard deviation of 1.52; the total number concentration was $810^{5} \# . \mathrm{cm}^{-3}$. Particles brought to Boltzmann equilibrium with a radioactive neutralizer $\left({ }^{241} \mathrm{Am}\right)$ were selected in the DMA (Grimm Vienna Type M-DMA), with a ratio of sheath airflow to aerosol flow set to 10 , in a range from $75 \mathrm{~nm}$ to $350 \mathrm{~nm}$. Mobility-classified particles selected by the DMA were then sent to the ELPI, as shown in Figure 4. Even though our experiments were carried out on liquid particles, the ELPI was equipped with greased PVC membranes (GLA 5000, Nuclepore) to minimize particle bouncing.

\section{Figure 4}

Preliminary experiments were carried out with HEPA-filtered air to determine the limit of quantification (LOQ) of the ELPI electrometers. For the range of currents considered in this study (10,000 fA), the results lead to a LOQ between $1.5 \mathrm{fA}$ and $2.9 \mathrm{fA}$, depending on the stage considered. Experimental data falling below the LOQ for each stage were excluded from analysis.

\section{Data analysis}

For each size selected, the current and number size distributions measured by the ELPI were used to determine the aerodynamic median diameters by means of the $50 \%$ percentile of the cumulative current distributions (approach " $A$ " in Table 2) and number distribution (approach "B" in Table 2), respectively. The latter diameters were then compared to the electrical mobility diameter to derive the corresponding particle effective density according to equation (1).

On the other hand, the number size distribution stemming from the SMPS were used as input parameters for the theoretical calculations as described in the previous section (see 
also Figure 1). This provides an estimation of particle effective density for each population (approaches "C1" to "C5", as defined in Table 2).

\section{Table 2}

\section{Validation criteria}

Because models cannot perfectly predict the current distribution in the ELPI because of various mechanisms that are not accounted for in the computations (e.g. particle transport efficiency, aerosol dilution, etc.), criteria were defined to validate the method, based on experimental data. Moreoever, the use of ELPI data is crucial when measuring unknown airborne particles. Indeed, in the absence of "reference" effective density, such criteria based on experimental data are necessary to ensure the robustness of results mainly based on theoretical calculations.

Thus, the experimental current distribution from the ELPI $\left(I_{i}^{\exp }\right)$ was corrected using the theoretical fraction of $p$-charged particles in each channel, stemming from the theoretical computations based on the SMPS number size (dashed box in Figure 1):

$I_{i}^{\text {exp,corr }}(p)=I_{i}^{\text {exp }} \cdot \frac{I_{i}^{\text {theo }}(p)}{\sum_{p=1}^{p=5} I_{i}^{\text {theo }}(p)}$

where $I_{i}^{\text {theo }}(p)$ corresponds to the theoretical current on stage $i$ as a result of the presence of population $p$ (equation (10)). The relative current distributions $R I_{i}^{\text {exp,corr }}(p)$ and $R I_{i}^{\text {theo }}(p)$ defined by:

$R I_{i}^{\text {exp,corr }}(p)=\frac{I_{i}^{\text {exp,corr }}(p)}{\sum_{i=1}^{i=12} I_{i}^{\text {exp,corr }}(p)}, \quad R I_{i}^{\text {theo }}(p)=\frac{I_{i}^{\text {theo }}(p)}{\sum_{i=1}^{i=12} I_{i}^{\text {theo }}(p)}$

were then compared.

In practice, the following relative discrepancy $\Delta^{\prime}(p)$ :

$\Delta^{\prime}(p)=\frac{R I_{i}^{\text {exp,corr }}(p)-R I_{i}^{\text {theo }}(p)}{R I_{i}^{\text {theo }}(p)} \cdot 100$

was calculated for each population $p$ for the stage $i$ on which the maximum relative current was measured. Relative discrepancies of up to $25 \%$ were chosen to represent an acceptable level when validating the approach. 


\section{Results and discussion}

Five different electrical mobility diameters were selected in the DMA, ranging from 75 $\mathrm{nm}$ to $350 \mathrm{~nm}$. The corresponding effective densities are shown in Figure 5 for the different approaches defined in Table 2.

\section{Figure 5}

The particle effective densities were quite variable with approaches " $A$ " \& "B" for the different particle sizes (Figure 5). More precisely, the relative discrepancies ( $\Delta$, equation (11)) found were between $-6 \%$ and $+147 \%$ for approach " $A$ ", and between $-10 \%$ and $+141 \%$ for approach "B". Consequently, the ELPI signal - whether expressed as current or number size distribution - should be taken with caution when seeking to accurately determine the aerodynamic equivalent diameter of DMA-selected particles. Again, this bias is not due to the ELPI itself, but is related to the presence of multiply-charged particles at the outlet of the DMA. However, the intrinsic charging law of the ELPI will give more weight to these unwanted populations, especially in the particle current distribution (approach "A"), and to a lesser extent in the number size distribution (approach "B").

The relative discrepancies found for selected particles of both $215 \mathrm{~nm}$ and $350 \mathrm{~nm}$ were below the validation threshold. This could be due to the width of the corresponding ELPI stages concerned - 100 and $120 \mathrm{~nm}$ large, respectively.

Figure 5 shows that the densities computed from the SMPS measurement of number size distribution are the closest to the true density of $0.914 \mathrm{~g} . \mathrm{cm}^{-3}$ ("C $\mathrm{C} p$ ", Table 2). Indeed, the relative discrepancies, $\Delta$, with this technique range from $-8 \%$ to $+11 \%$, whatever the population $p$ considered.

Since the SMPS used to measure particle number size distribution was used with a medium DMA, the range of sizes covered is limited to $5.5-350 \mathrm{~nm}$. In other words, no information on number concentration is available for particles greater than $350 \mathrm{~nm}$ in diameter. Consequently, it is not possible to calculate the discrepancy for multiplycharged particles with an equivalent mobility diameter greater than this limit. This corresponds to population 5 for DMA-selected sizes greater than $125 \mathrm{~nm}$, populations 3 and above for 191-nm particles, and populations 2 and above for 350-nm particles.

An example of the use of the ELPI signal to validate the calculations is provided in Figure 6, where theoretical and corrected experimental relative current distributions are 
compared for $125 \mathrm{~nm}$ DMA-selected particles. The corresponding relative discrepancies $\Delta^{\prime}$ - as defined by equation (14) - are shown in Table 3.

\section{Figure 6}

\section{Table 3}

Figure 6 shows an acceptable agreement between theoretical and corrected experimental relative distributions, for all the populations considered. Once again, this finding is important because (1) it is based on experimental ELPI data, and (2) it can be used to validate the theoretical calculations.

Like in Table 3, all (relevant) relative discrepancies $\Delta^{\prime}$ were between $-20 \%$ and $+21 \%$, thus below the $25 \%$ threshold for validation. Moreover, although ELPI data below the LOQ was measured for $75-\mathrm{nm}$ particles carrying 4 and 5 charges, the densities obtained are consistent with those found for the other populations (Figure 5). This problem with the LOQ is one of the major limitations of the tandem DMA/ELPI setup, stemming from the fact that DMA-selected particles must be extensively diluted (by a factor of roughly 30). Thus, high initial particle concentrations must be generated to ensure that a relevant current distribution will be measured in the ELPI and that data will be valid.

To improve the method, it might be possible to use a (complex) inversion algorithm to refine the size resolution of the ELPI. This would help better estimate the corresponding aerodynamic diameter of DMA-selected particles, whatever the approach considered. Indeed, a $10 \%$ variation in the aerodynamic diameter leads to a variation of roughly 100 $\mathrm{kg} \cdot \mathrm{m}^{-3}$ in the corresponding effective density, all other parameters being equal.

Furthermore, the absence of SMPS data above a certain particle diameter should be pointed out. Thus, for aerosols containing particles larger than e.g. $1 \mu \mathrm{m}$ (corresponding to the maximum size with a long DMA) cannot be treated by the method proposed. From our point of view, this method should therefore only be applied to a restricted range of aerosols whose size distribution is strictly within the range fixed by the DMA. Moreover, the results based on multiply-charged particles can be validated only when the corresponding electrical mobility diameters are within the size range of the SMPS distribution. In principle, multi-modal aerosols should not be problematic if the previous conditions are fulfilled. 


\section{Conclusion}

The present work presents a new method to measure the effective density of airborne particles based on the simultaneous measurement of the aerodynamic and the electrical mobility diameters of an aerosol (DMA/ELPI). The originality of this approach is that it can also handle multiply-charged particles exiting the DMA and measured by the ELPI. Calculations were performed to determine the theoretical contribution of each population within the ELPI current distribution based on the number size distribution provided by the SMPS, and thus the corresponding effective density. Using these fractions, the ELPI experimental signal was corrected and compared to theoretical values to validate the approach.

Experimental results for spherical DEHS particles show that: (1) neither the total current nor the total number size distribution measured by the ELPI can be used alone to accurately determine particle effective density, (2) the approach proposed based on multiple charging correction can estimate particle effective density within $\pm 15 \%$.

Among the limitations of the present method we list the following: highly concentrated aerosols should be used to ensure ELPI measurements above the electrometers' LOQ; and, the size distribution of the aerosols should be completely covered by the SMPS size range.

The data presented in this paper constitute the first measurement of particle effective density performed by the approach proposed. They should be considered as a first dataset requiring further substantiation. Among the remaining issues, the case of aggregates / agglomerates should be investigated. 


\section{References}

Ahlvik P., Ntziachristos L., Keskinen J. and Virtanen A. (1998). Real time measurement of diesel particle size distribution with an electrical low pressure impactor. SAE Technical Paper No 980410.

Bau S. and Witschger O. (2013). A modular tool for analyzing cascade impactors data to improve exposure assessment to airborne nanomaterials. Journal of Physics: Conference Series $\mathbf{4 2 9}$ 012002. doi: 10.1088/1742-6596/429/1/012002.

Charvet A., Bau S., Paez-Coy N.E., Bemer D. and Thomas D. (2014). Characterizing the effective density and primary particle diameter of airborne nanoparticles produced by spark discharge using mobility and mass measurements (tandem DMA/APM). Journal of Nanoparticle Research, submitted.

DeCarlo P. F., Slowik J. G., Worsnop D. R., Davidovits P. and Jimenez J. L. (2004). Particle morphology and density characterization by combined mobility and aerodynamic diameter measurements. Part 1: Theory. Aerosol Science and Technology 38: 1185-1205.

Dong Y., Hays M.D., Smith N.D. and Kinsey J.S. (2004). Inverting cascade impactor data for sizeresolved characterization of fine particulate source emissions. Journal of Aerosol Science 35: $1497-1512$.

Ehara K., Hagwood C. and Coakley K.J. (1996). Novel method to classify aerosol particles according to their mass-to-charge ratio - Aerosol Particle Mass Analyzer. Journal of Aerosol Science 27: 217-234.

Hand J.L. and Kreidenweis S.M. (2002). A new method for retrieving particle refractive index and effective density from aerosol size distribution data. Aerosol Science and Technology 36: 1012-1026.

Heim M., Kasper G., Reischl G. P. and Gerhart C. (2004). Performance of a new commercial electrical mobility spectrometer. Aerosol Science and Technology 38: 3-14.

Hinds W.C. (1999). Aerosol Technology. Properties, behavior and measurement of airborne particles ( $2^{\text {nd }}$ Edition), New York: John Wiley \& Sons, $483 \mathrm{p}$.

Huuluvainen H., Arffman A., Saukko E., Virtanen A. and Keskinen J. (2013). A new method for characterizing the bounce and charge transfer properties of nanoparticles. Journal of Aerosol Science 55: 104-115.

ICRP (1994). Publication 66: Human respiratory tract model for radiological protection. Oxford: Pergamon.

Katrib Y., Martin S.T., Rudich Y., Davidovits P., Jayne J.T. and Worsnop D.R. (2005). Density changes of aerosol particles as a result of chemical reaction. Atmospheric Chemistry and Physics 5: 275-291.

Kelly W.P. and Mc Murry P.H. (1992). Measurement of particle density by inertial classification of Differential Mobility Analyzer-generated monodisperse aerosols. Aerosol Science and Technology 17: 199-212.

Keskinen J., Pietarinen K. and Lehtimäki M. (1992). Electrical low pressure impactor. Journal of Aerosol Science 23: 353-360. 
Kim S.H., Mulholland G.W. and Zachariah M.R. (2009). Density measurement of size selected multiwalled carbon nanotubes by mobility-mass characterization. Carbon 47: 1297-1302.

Ku B.K., Emery M.S., Maynard A.D., Stolzenburg M.R. and Mc Murry P.H. (2006). In situ structure characterization of airborne carbon nanofibres by a tandem mobility-mass analysis. Nanotechnology 17: 3613-3621.

Ku B.K. and Kulkarni P. (2012). Comparison of diffusion charging and mobility-based methods for measurement of aerosol agglomerate surface area. Journal of Aerosol Science 47: 100110.

Maricq M.M., Podsiadlik D.H. and Chase R.E. (2000). Size distributions of motor vehicle exhaust PM: a comparison between ELPI and SMPS measurements. Aerosol Science and Technology 33: 239-260.

Maricq M.M., Xu N. and Chase R.E. (2006). Measuring particulate mass emissions with the Electrical Low Pressure Impactor. Aerosol Science and Technology 40: 68-79.

Marjamäki M., Keskinen J., Chen D.-R. and Pui D. Y. H. (2000). Performance evaluation of the Electrical Low-Pressure Impactor (ELPI), Journal of Aerosol Science 31: 249-261.

Marjamäki M., Lemmetty M. and Keskinen J. (2005). ELPI response and data reduction. I: Response functions. Aerosol Science and Technology 39: 575-582.

Martinsson B.G., Karlsson M.N.A. and Frank G. (2001). Methodology to estimate the transfer function of individual differential mobility analyzers. Aerosol Science and Technology 35: $815-823$

Mc Murry P.H., Wang X., Park K. and Ehara K. (2002). The relationship between mass and mobility for atmospheric particles: A new technique for measuring particle density. Aerosol Science and Technology 36:227-238.

Moisio M. (1999). Real-time size distribution measurement of combustion aerosols. $\mathrm{PhD}$ thesis, Univeristy of Tempere, Finland. ISBN 952-15-0328-9.

NCRP (1997). Deposition, retention and dosimetry of inhaled radioactive substances, Report S.C. 57-2, NCRP, Bethesda, MD.

Ouf F.-X. and Sillon P. (2009). Charging efficiency of the electrical low pressure impactor's corona charger: Influence of the fractal morphology of nanoparticle aggregates and uncertainty analysis of experimental results. Aerosol Science and Technology 43: 685-698.

Pagels J., Khalizov A.F., Mc Murry P.H. and Zhang R.Y. (2009). Processing of soot by control sulphuric acid and water condensation - mass and mobility relationship. Aerosol Science and Technology 43: 629-640.

Qi C., Asbach C., Shin W.G., Fissan H. and Pui D.Y.H. (2009). The effect of particle pre-existing charge on unipolar harging and its implication on electrical aerosol measurement. Aerosol Science and Technology 43: 232-240

Rissler J., Messing M.E., Malik A.I., Nilsson P.T., Nordin E.Z., Bohgard M., Sanati M. and Pagels J.H. (2013). Effective density characterization of soot agglomerates from various sources and comparison to aggregation theory. Aerosol Science and Technology 47: 792-805. 
Ristimäki J., Virtanen A., Marjamäki M., Rostedt A. and Keskinen J. (2002). On-line measurement of size distribution and effective density of submicron aerosol particles. Journal of Aerosol Science 33: 1541-1557.

Ristimäki J. and Keskinen J. (2006). Mass measurement of non-spherical particles: TDMA-ELPI setup and performance tests. Aerosol Science and Technology 40: 997-1001.

Schmid O., Karg E., Hagen D.E., Whitefield P.D. and Ferron G.A. (2007). On the effective density of non-spherical particles as derived from combined measurements of aerodynamic and mobility equivalent size. Journal of Aerosol Science 38: 431-443.

Shapiro M., Vainshtein P., Dutcher D., Emery M., Stolzenburg M., Kittelson D.B. and Mc Murry P.H. (2012). Characterization of agglomerates by simultaneous measurement of mobility, vacuum aerodynamic diameter and mass. Journal of Aerosol Science 44: 24-45.

Skillas G., Burtscher H., Siegmann K. and Baltensperger U. (1999). Density and fractal-like dimension of particles from a laminar diffusion flame. Journal of Colloid and Interface Science 217: 269-274.

Stein S.W., Turpin B.J., Cai X., Huang P.F. and Mc Murry P.H. (1994). Measurements of relative humidity-dependent bounce and density for atmospheric particles using the DMA-impactor technique. Atmospheric Environment 28: 1739-1746.

Stolzenburg M. R. (1988). An Ultrafine Aerosol Size Distribution Measuring System. Ph.D. Thesis. University of Minnesota.

Stratmann F. (1997). Differential electrical mobility analysis: A theoretical study. Aerosol Science and Technology 26: 368-383.

Van Gulijk C., Marijnissen J.C.M., Makkee M., Moulijn J.A. and Schmidt-Ott A. (2004). Measuring diesel soot with a scanning mobility particle sizer and an electrical low-pressure impactor: performance assessment with a model for fractal-like agglomerates. Journal of Aerosol Science 35:633-65.

Virtanen A., Marjamäki M., Ristimäki J. and Keskinen J. (2001). Fine particle losses in electrical low pressure impactor. Journal of Aerosol Science 32: 389-401.

Virtanen A., Ristimäki J. and Keskinen J. (2004). Method for measuring effective density and fractal dimension of aerosol agglomerates. Aerosol Science and Technology 38:437-446.

Virtanen A., Kannosto J., Huuvulainen H., Arffman A., Joutsensaari J., Saukko E., Hao L., YliPirilä P., Tiitta P., Holopainen J.K., Keskinen J., Wornsop D.R., Smith A. and Laaksonen A. (2011). Bounce behavior of freshly nucleated biogenic secondary aerosol particles. Atmospheric Chemistry and Physics 11: 8759-8766.

Zeleniuk A., Cai Y., Chieffo L. and Imre D. (2005). High precision density measurements of single particles: The density of metastable phases. Aerosol Science and Technology 39: 972-986.

Zeleniuk A., Cai Y. and Imre D. (2006). From agglomerates of spheres to irregularly shaped particles: Determination of dynamic shape factors from measurements of mobility and vacuum aerodynamic diameters. Aerosol Science and Technology 40: 197-217. 


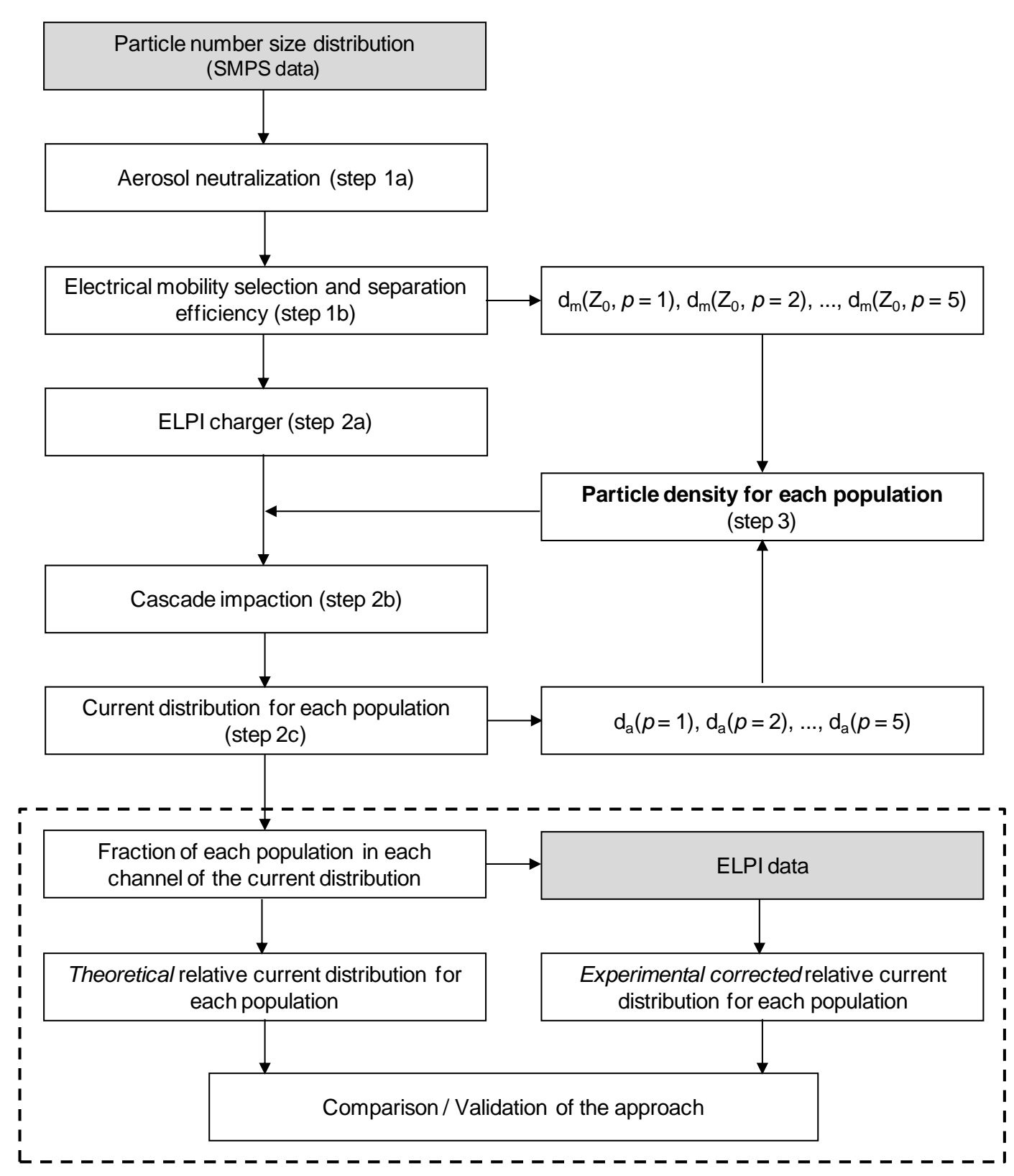

Figure 1. Flowchart showing the method used to determine particle effective density. 


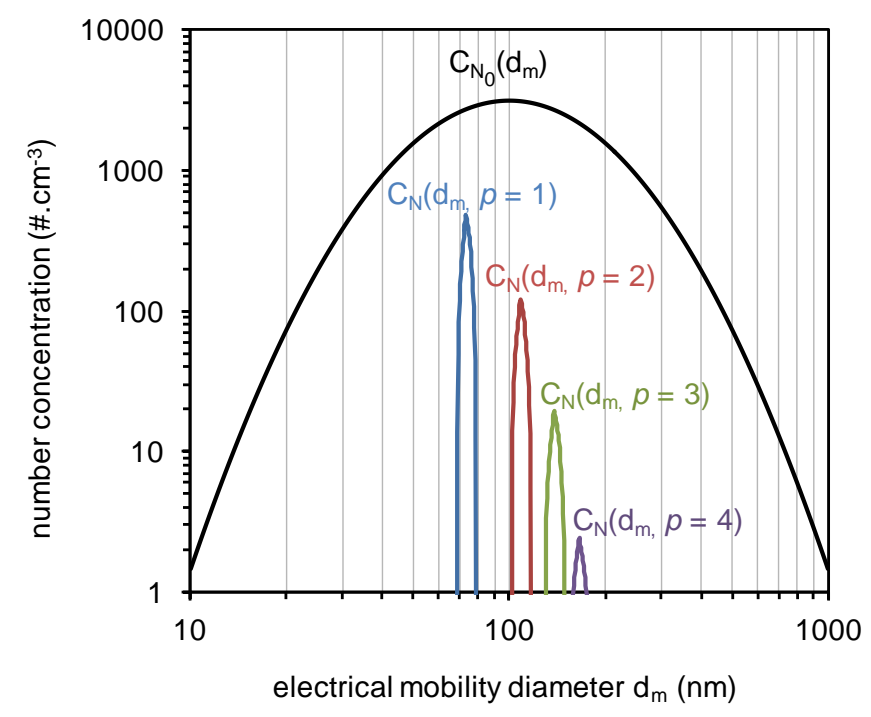

Figure 2. Particle number size distributions at the inlet $-C_{N_{0}}\left(d_{m}\right)$ - and outlet $-C_{N}\left(d_{m}, p=1\right)$, $C_{N}\left(d_{m}, p=2\right), C_{N}\left(d_{m}, p=3\right), C_{N}\left(d_{m}, p=4\right)$ - of the DMA for the theoretical aerosol considered (lognormal distribution with a mode of $100 \mathrm{~nm}$, a geometric standard deviation of 1.8 , and a total concentration of $10^{6} \# \cdot \mathrm{cm}^{-3}$, particle density $\rho_{e}=2 \mathrm{~g} . \mathrm{cm}^{-3}$ ) and DMA selection at 75 $\mathrm{nm}$. 

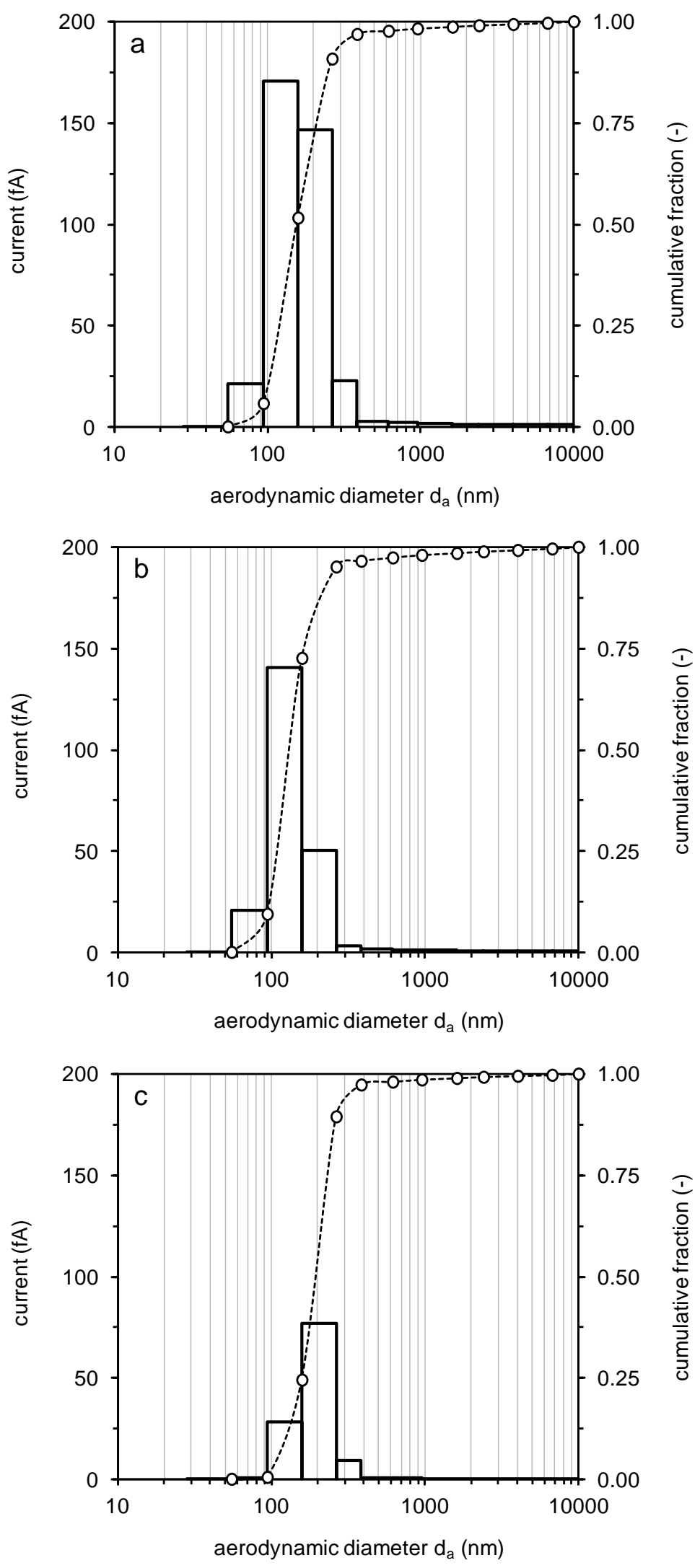

Figure 3. Current distributions (left axis) and current cumulative fractions (right axis) calculated for the theoretical aerosol considered. a- total current, b- singly charged particles only, c- doubly charged particles only. 


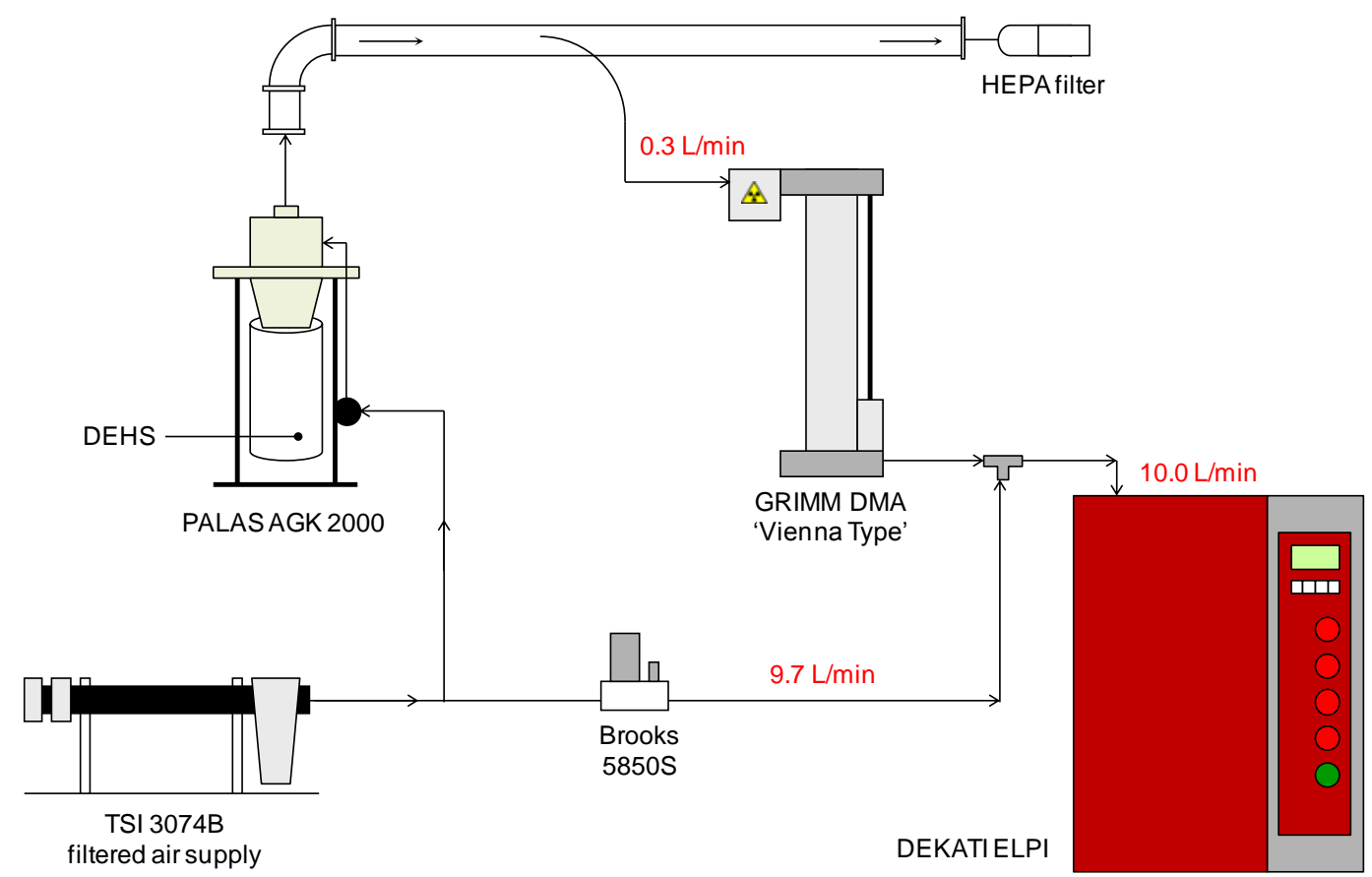

Figure 4. Diagram of the experimental setup. 


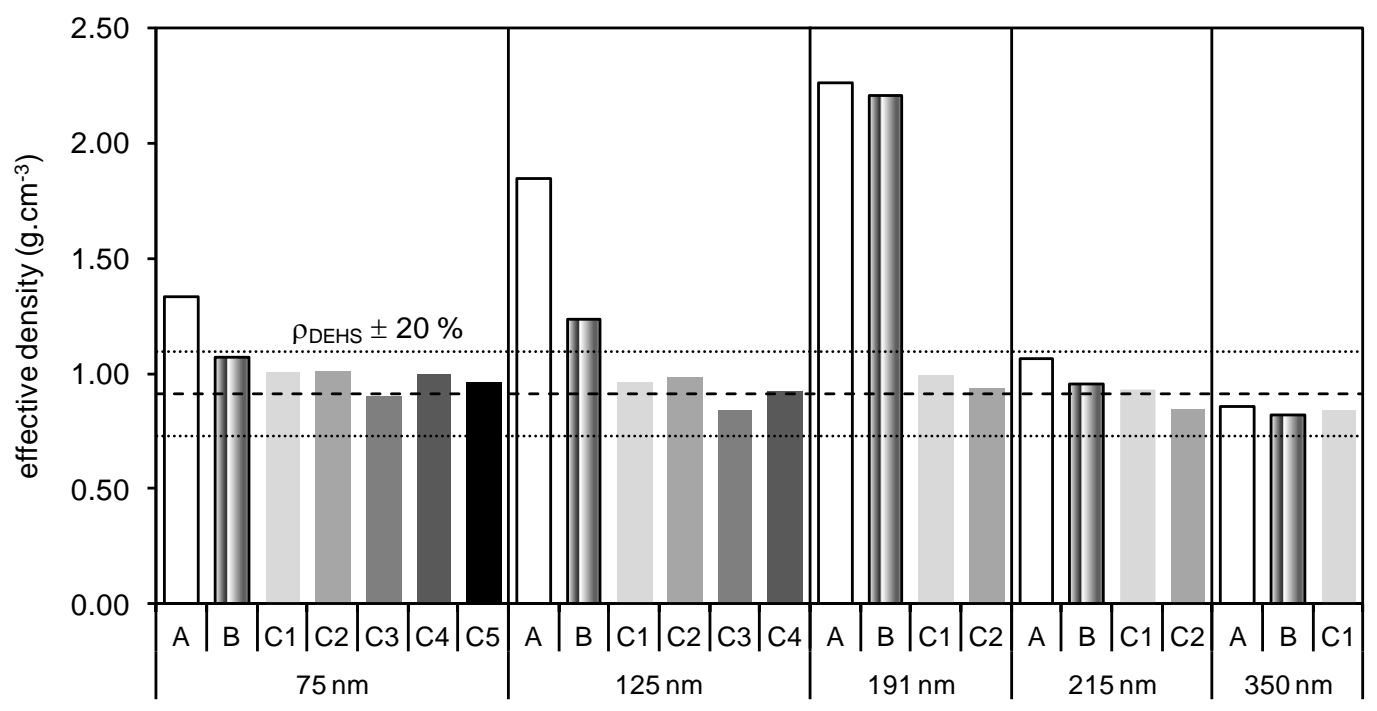

Figure 5. Comparison of the effective density of spherical DEHS particles determined using different approaches for three sizes selected using a DMA. "A", "B" and " $\mathrm{C} p$ " refer to the different approaches used to determine the aerodynamic equivalent diameter presented in Table 2. 

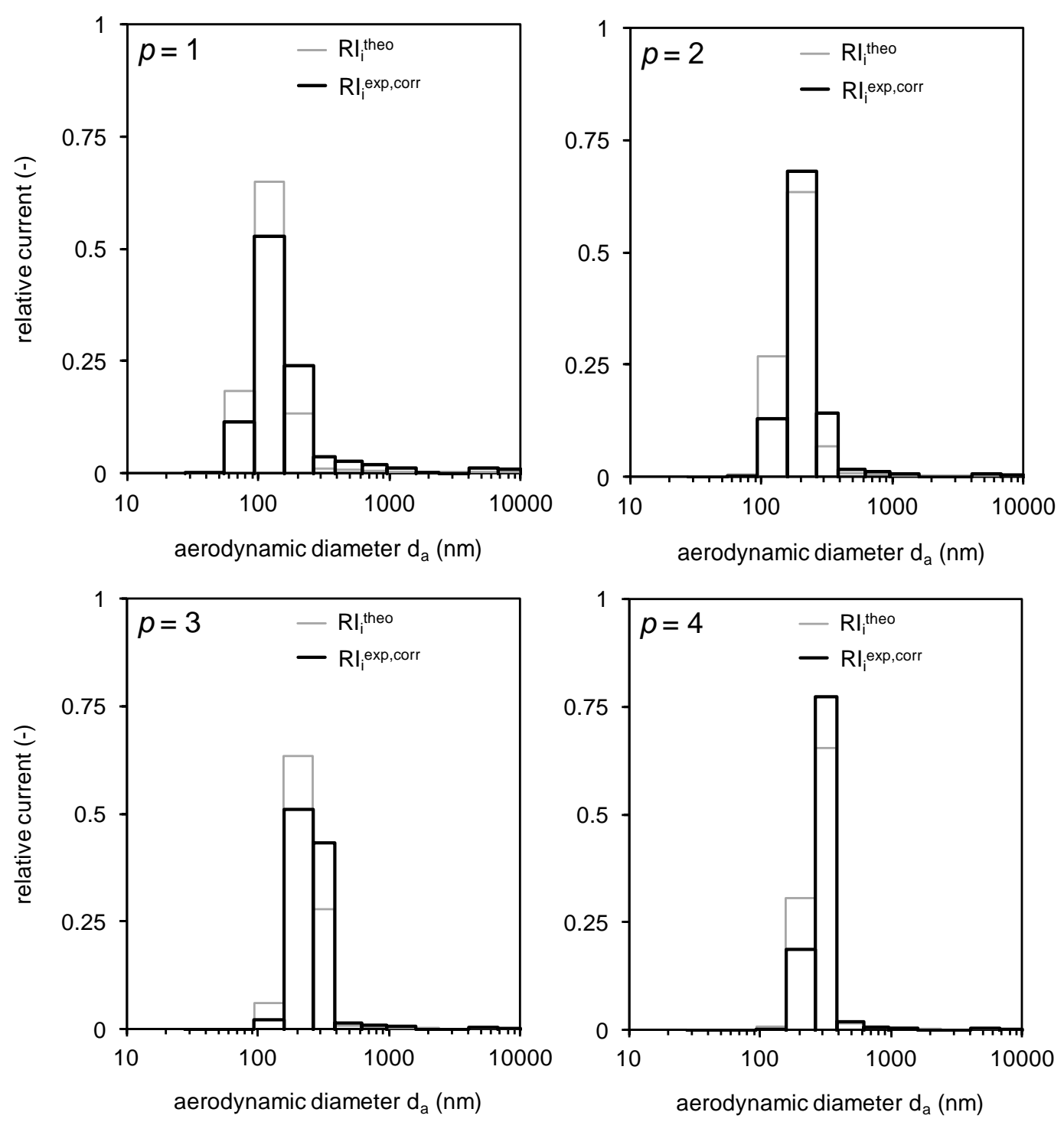

Figure 6. Comparison of the relative current distributions for each population $(p=1, \ldots, 4)$ for DMA-selected particles with an electrical mobility diameter of $125 \mathrm{~nm}$. The grey histograms represent the theoretical relative current distributions; the black histograms represent the corrected experimental relative current distributions. 
Table 1. Effective densities obtained for the different populations in the theoretical aerosol considered $\left(\rho_{e}=2\right.$ g.cm $\left.{ }^{-3}\right)$.

\begin{tabular}{|c|c|c|c|c|}
\hline Population & $d_{m}(\mathrm{~nm})$ & $d_{a}(\mathrm{~nm})$ & $\rho_{e}^{\text {calc }}\left(\mathrm{g} \cdot \mathrm{cm}^{-3}\right)$ & $\Delta(\%)$ \\
\hline total & 75 & 155 & 2.546 & 27.3 \\
\hline$p=1$ & 75 & 131 & 2.026 & 1.3 \\
\hline$p=2$ & 111 & 193 & 2.139 & 7.0 \\
\hline$p=3$ & 141 & 224 & 1.941 & -2.9 \\
\hline$p=4$ & 169 & 275 & 2.067 & 3.3 \\
\hline$p=5$ & 195 & 302 & 1.962 & -1.9 \\
\hline
\end{tabular}


Table 2. Definition of the aerodynamic equivalent diameter in the different approaches

\begin{tabular}{|l|l|l|}
\hline Approach & \multicolumn{2}{|l|}{ Median aerodynamic diameter derived from } \\
\hline A & measured & current size distribution \\
\hline B & measured & number size distribution \\
\hline C $p$ & calculated & current size distribution for population $p(p=1$ to 5) \\
\hline
\end{tabular}


Table 3. Relative discrepancies $\Delta^{\prime}$ between theoretical and corrected experimental current distributions for the different populations in each size selected.

\begin{tabular}{|c|c|c|c|c|c|}
\hline Population & $d_{m}=75 \mathrm{~nm}$ & $d_{m}=125 \mathrm{~nm}$ & $d_{m}=191 \mathrm{~nm}$ & $d_{m}=215 \mathrm{~nm}$ & $d_{m}=350 \mathrm{~nm}$ \\
\hline$p=1$ & $10 \%$ & $-19 \%$ & $6 \%$ & $9 \%$ & $10 \%$ \\
\hline$p=2$ & $3 \%$ & $8 \%$ & $7 \%$ & $-9 \%$ & N.A. \\
\hline$p=3$ & $21 \%$ & $-20 \%$ & N.A. & N.A. & N.A. \\
\hline$p=4$ & $*$ & $18 \%$ & N.A. & N.A. & N.A. \\
\hline$p=5$ & $*$ & N.A. & N.A. & N.A. & N.A. \\
\hline
\end{tabular}

N.A. not applicable due to SMPS size range limit

* ELPI data below the LOQ 